УДК 378.147

\title{
РАЗВИТИЕ ИННОВАЦИОННЫХ ТЕХНОЛОГИЙ ОБУЧЕНИЯ ОСНОВАМ РЫНОЧНОЙ ЭКОНОМИКИ СТУДЕНТОВ ТЕХНИЧЕСКИХ И ЛОГИСТИЧЕСКОГО НАПРАВЛЕНИЙ ПОДГОТОВКИ
}

\author{
Андреева Александра Андреевна \\ к.э.н., доцент каф. ЭМФ \\ Быстров Олег Филаретович \\ д.э.н., профессор каф. ЭМФ
}

Научный руководитель: Ермошина Галина Петровна к.э.н., зав. каф. ЭМФ

ФГАОУ ВО «Московский институт электронной техники»

Аннотация: Элементарная грамотность современного человека предполагает знание основ рыночной экономики. Овладение прикладными аспектами рыночной экономики является непременным условием коммерциализации любых новаций в технике и логистике. Данная статья посвящена вопросам адаптации учебной программы и технологии организации учебного процесса дисциплины «Основы рыночной экономики» к специфике технических и логистического направлений подготовки.

Ключевые слова: рыночная экономика, предпринимательство, логистика, метод БОФа.

\section{DEVELOPMENT OF INNOVATIVE TEACHING TECHNOLOGIES IN THE BASIS OF MARKET ECONOMY FOR STUDENTS OF TECHNICAL AND LOGISTICS TRAINING}

\author{
Andreeva Aleksandra Andreevna \\ Bystrov Oleg Filaretovich \\ Scientific adviser: Ermoshina Galina Petrovna
}

\begin{abstract}
Elementary literacy of a modern person presupposes knowledge of the fundamentals of a market economy. The applied aspects of the market economy is an important condition for the commercialization of any innovations in
\end{abstract}


technology and logistics. This article is devoted to the adaptation of the curriculum and the technology of organizing the educational process of the discipline "Fundamentals of a Market Economy" to the specifics of technical and logistic areas of training.

Keywords: market economy, entrepreneurship, logistics, BOF method.

Выпускники высших учебных заведений технических и логистического направлений подготовки в условиях рыночной экономики неизбежно сталкиваются с технологическим предпринимательством. В этой связи объективно возникает необходимость ознакомления студентов с основами рыночной экономики, а также практического освоения ими методов, методик и алгоритмов прикладного характера, представляющих собой методический инструментарий управления бизнес-процессами в сфере инноваций.

Учет этого требования в основной программе высшего профессионального образования для данной категории обучаемых приводит к внедрению как в саму программу, так и в технологию организации учебного процесса соответствующей специфики.

В этой связи остановимся на некоторых инновационных наработках в этом направлении, которые, по мнению авторов могли бы способствовать дальнейшему прогрессу образовательных технологий.

\section{Адаптация учебного материала к профилю подготовки обучаемых}

Главным результатом подобной трансформации учебного материала, несомненно, служит рабочая учебная программа дисциплины «Основы рыночной экономики», включающая следующие темы [1]:

1. Экономика как объект изучения. Экономические ресурсы и экономический выбор.

2. Рынок и рыночное регулирование экономики.

3. Предпринимательская деятельность. Стартапы.

4. Капитал. Эффективность использования капитала.

5. Рынок труда и его особенности.

6. Финансовый рынок.

7. Конкурентоспособность.

8. Динамика производственного процесса в условиях информационного общества. Цифровая экономика.

9. Метрология макроэкономических процессов и макроэкономическая нестабильность. 


\section{0. Экономическая роль государства и экономическая политика.}

Это лишь возможный пример формирования тематики учебной дисциплины. Содержательная ее часть в каждом конкретном случае должна стать предметом профессионального обсуждения.

\section{Модификация и модернизация методов обучения}

При активном использовании современных методов обучения (рис. 1) преподаватели должны быть постоянно озабочены вопросами их совершенствования и приспособления к конкретным контингентам обучаемых и изменяющимся условиям ведения образовательной деятельности.

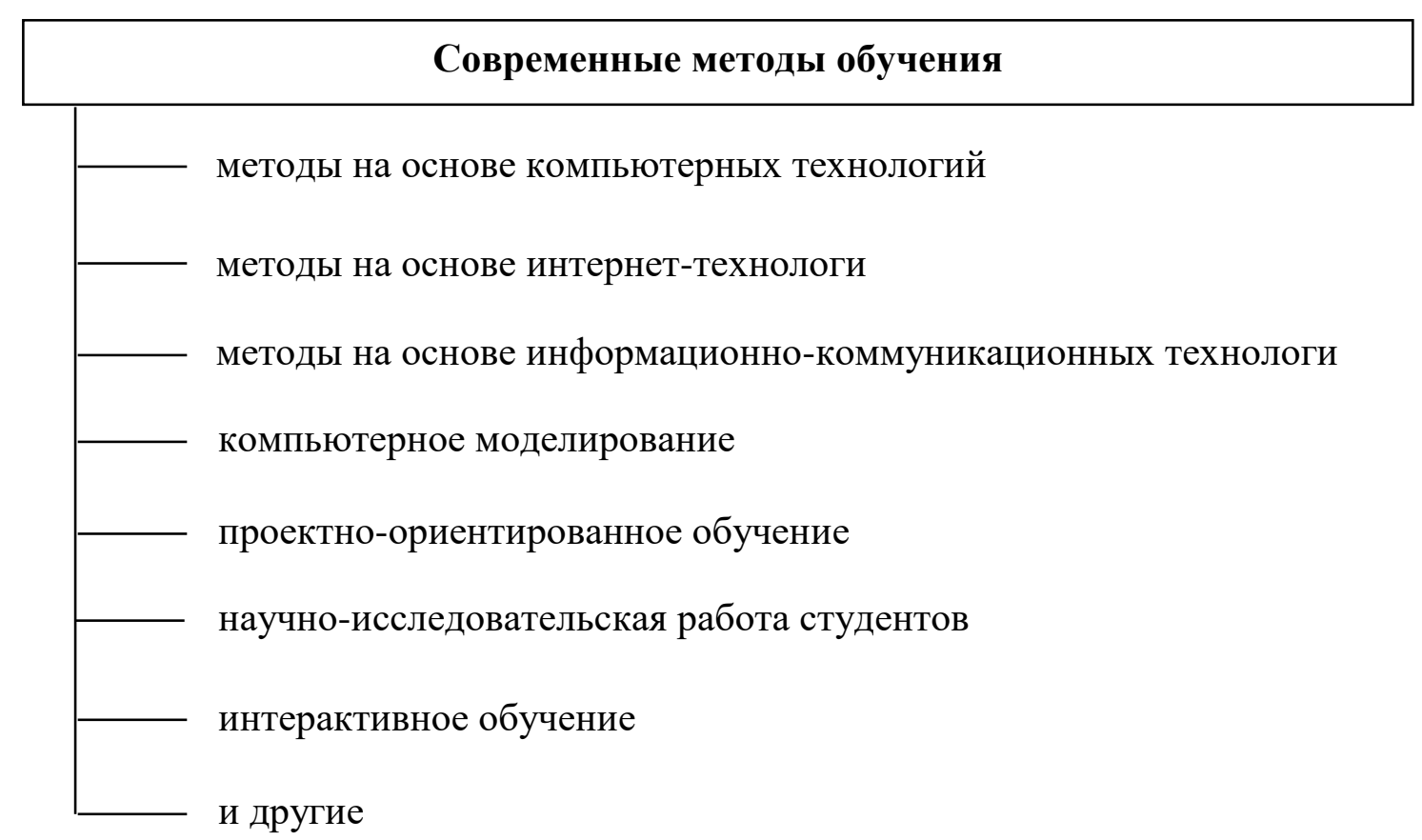

\section{Рис. 1. Современные методы обучения}

Обратимся к конкретному примеру. Довольно часто при обучении студентов методологически важному методу решения конкретной прикладной задачи возникает проблемный вопрос о закреплении полученных ими знаний, умений и навыков. Разрешение проблемы осуществляется в процессе самостоятельного решения индивидуального варианта поставленной задачи с использованием изученного метода. Возникает необходимость тиражирования базового варианта задачи с изменением исходных данных в нем. Количество вариантов должно быть равно числу студентов в группе. Авторы предлагают осуществлять это с использованием личных мобильных телефонов, имеющих выход в интернет. Покажем это на простейшем примере [1]. 
Требуется построить кривую производственных возможностей исходя из данных в таблице 1.

Таблица 1

\begin{tabular}{|c|c|c|}
\hline Варианты & Товар $A$, ед. & Товар $B$, ед. \\
\hline 1 & 3000 & 100 \\
\hline 2 & 2000 & 300 \\
\hline 3 & 500 & 500 \\
\hline
\end{tabular}

Задача решается для личного варианта исходных данных. Вариант формируется следующим образом: две последние цифры в каждом значении таблицы 1 заменяются на случайное число (с помощью генератора случайных чисел мобильного телефона) из интервала от 11 до 99, то есть применяется рандомизация вида $R(11,99)$.

Формирование множества вариантов произвольной мощности с использованием подобной рандомизации оказалось чрезвычайно востребованным особенно в условиях дистанционного обучения, вызванного пандемией.

Качество усвоения учебных материалов дисциплины рекомендуется оценивать по выполненным студентами сборникам отчётных материалов по всем занятиям. При этом методическое обеспечение каждого занятия должно содержать перечень отчетных материалов. Пример отчета по заданию для самостоятельного выполнения студентами приведен ниже [1].

С учетом конкурентной позиции фирмы требуется определить цену на инновационный товар, выводимый на рынок.

По результатам маркетинговых исследований отобраны 10 компанийконкурентов с товарами - аналогами. Цены на товары-аналоги представлены в таблице 2.

Таблица 2

\begin{tabular}{|c|c|c|c|c|c|c|c|c|c|c|}
\hline Компания & 1 & 2 & 3 & 4 & 5 & 6 & 7 & 8 & 9 & 10 \\
\hline $\begin{array}{l}\text { Цена за единицу } \\
\text { конкретного товара }\end{array}$ & 7815 & 7503 & 7666 & 7858 & 7674 & 7075 & 7853 & 7847 & 7896 & 7413 \\
\hline
\end{tabular}

Примечание: цена для индивидуального варианта формируется по зависимости.

$$
Ц=7000+R(111,999)
$$

с использованием генератора случайных чисел. 
Имеется также рейтинг конкурентоспособности сравниваемых компаний, представленный в таблице 3.

Таблица 3

\begin{tabular}{|c|c|c|c|c|c|c|c|c|c|c|c|}
\hline Компания & 1 & 2 & 3 & 4 & 5 & 6 & 7 & 8 & 9 & 10 & Исследуемая фирма \\
\hline $\begin{array}{c}\text { Рейтинговая } \\
\text { оценка }\end{array}$ & 4 & 1 & 6 & 2 & 10 & 5 & 8 & 9 & 3 & 11 & 7 \\
\hline
\end{tabular}

Отчётные материалы по заданию должны включать:

1) таблицу с личным вариантом данных по ценам;

2) график;

3) вывод: значение ориентировочной цены товара с учетом конкурентной позиции фирмы.

Ниже приведен отчет одного из студентов по данному заданию.

Отчет по практическому заданию на тему «Предпринимательская деятельность»

1. По результатам исследований отобраны 10 компаний-конкурентов (табл. 4).

Таблица 4

\begin{tabular}{|l|c|c|c|c|c|c|c|c|c|c|}
\hline Компания & 1 & 2 & 3 & 4 & 5 & 6 & 7 & 8 & 9 & 10 \\
\hline $\begin{array}{l}\text { Цена за единицу } \\
\text { товара }\end{array}$ & 7675 & 7991 & 7841 & 7592 & 7692 & 7230 & 7823 & 7478 & 7947 & 7301 \\
\hline
\end{tabular}

2. График (рис. 2), на котором представлено облако значений цены, соответствующих различным рейтинговым оценкам, с наложенным на него трендом-полиномом (рейтинговая оценка; цена на товар).

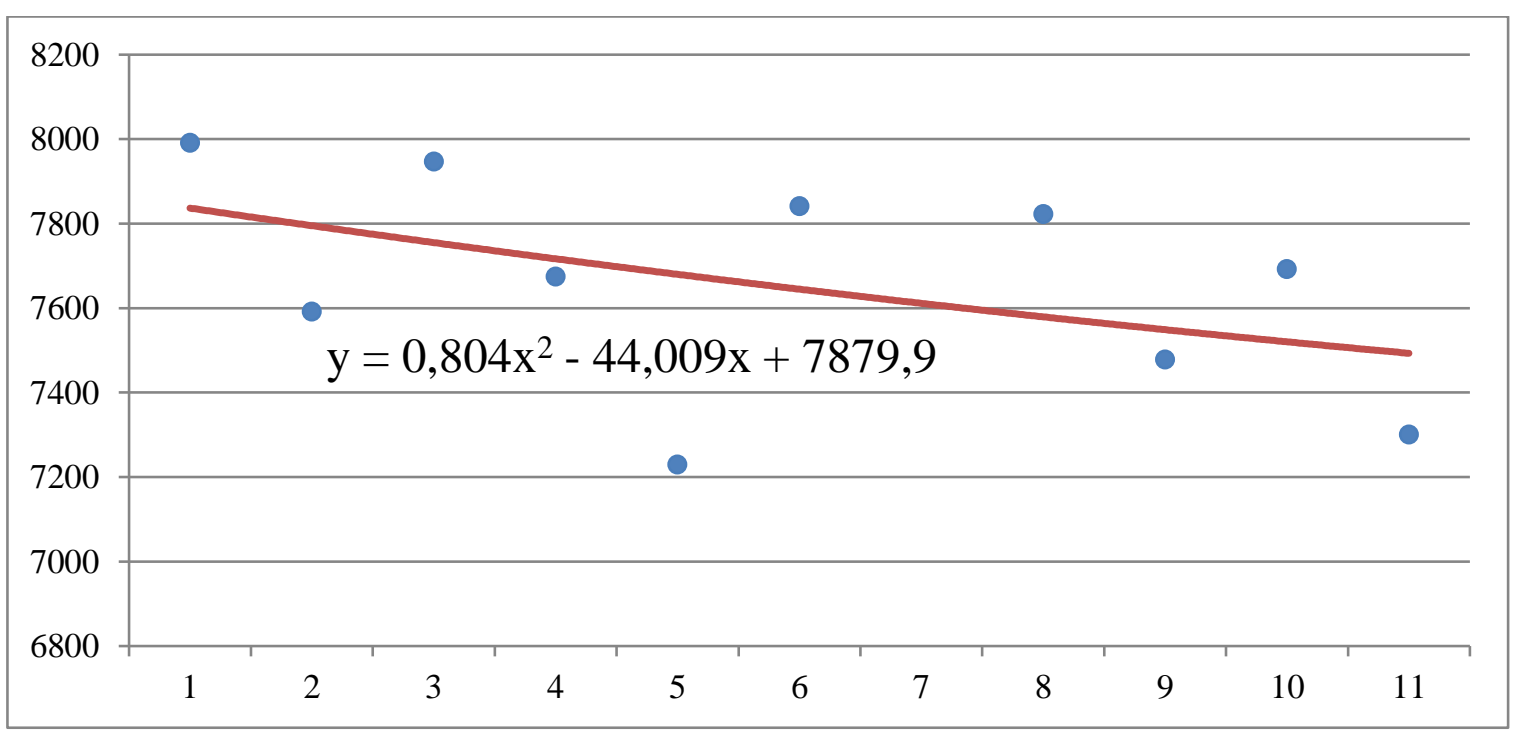

Рис. 2. Пример графика-отчета по заданию 
3. Цена-ориентир, вычисленная по уравнению тренда:

$$
0.804 * 7^{2}-44.009 * 7+7879.9=7611.2
$$

Подобные отчеты по всем без исключения занятиям каждым студентом перед промежуточной аттестацией объединяются в сборник, который высылается преподавателю.

Преподаватель оценивает сборник отчетов с использованием принятой системы показателей по следующей методике [2].

\section{Алгоритм методики}

1. Формирование системы показателей (табл. 5).

Таблица 5

\begin{tabular}{|c|c|c|c|c|}
\hline $\mathrm{W} 1$ & $\mathrm{~W} 2$ & $\mathrm{~W} 3$ & $\mathrm{~W} 4$ & $\mathrm{~W} 5$ \\
\hline $\begin{array}{c}\text { Степень усвоения } \\
\text { программного } \\
\text { материала }\end{array}$ & $\begin{array}{c}\text { Умение применять } \\
\text { теоретические } \\
\text { знания на практике }\end{array}$ & $\begin{array}{c}\text { Полнота и } \\
\text { качество } \\
\text { выполнения } \\
\text { заданий }\end{array}$ & $\begin{array}{c}\text { Умение } \\
\text { использовать } \\
\text { научный язык }\end{array}$ & Креативность \\
\hline
\end{tabular}

2. Ранжирование показателей по важности (табл. 6).

Таблица 6

\begin{tabular}{|c|c|c|c|c|}
\hline W1 & W2 & W3 & W4 & W5 \\
\hline 4 & 3 & 2 & 1 & 5 \\
\hline
\end{tabular}

Примечание: чем больше ранг, тем важнее показатель; значения рангов в случае одинаковой важности двух или более различных показателей могут совпадать.

3. Расчет коэффициентов важности показателей путем нормирования каждой ранговой оценки суммой всех ранговых оценок (табл. 7).

Таблица 7

\begin{tabular}{|c|c|c|c|c|}
\hline $\mathrm{C} 1$ & $\mathrm{C} 2$ & $\mathrm{C} 3$ & $\mathrm{C} 4$ & $\mathrm{C} 5$ \\
\hline 0,267 & 0,2 & 0,133 & 0,067 & 0,333 \\
\hline
\end{tabular}

4. Оценивание представленного студентом сборника по каждому частному показателю с использованием 5-балльной шкалы (табл. 8).

Таблица 8

\begin{tabular}{|c|c|c|c|c|}
\hline $\begin{array}{c}\text { Степень } \\
\text { усвоения } \\
\text { программного } \\
\text { материала }\end{array}$ & $\begin{array}{c}\text { Умение применять } \\
\text { теоретические } \\
\text { знания на практике }\end{array}$ & $\begin{array}{c}\text { Полнота и } \\
\text { качество } \\
\text { выполнения } \\
\text { заданий }\end{array}$ & $\begin{array}{c}\text { Умение } \\
\text { использовать } \\
\text { научный язык }\end{array}$ & Креативность \\
\hline В1=3 & 4 & 3 & 4 & 2 \\
\hline
\end{tabular}


5. Свертка значений всех оценок частных показателей в обобщенный показатель $(\overline{\mathrm{B}})$ по формуле:

$$
\overline{\mathrm{B}}=\sum \mathrm{Cj} \times \mathrm{Bj}
$$

Для данного примера имеем:

$$
\overline{\mathrm{B}}=3 \times 0,267+4 \times 0,2+3 \times 0,133+4 \times 0,067+2 \times 0,333=2,9
$$

Преподаватель вправе округлить полученную оценку до целого значения.

Использование рассмотренных выше положений призвано способствовать развитию у обучаемых знаний, умений и навыков, необходимых для решения прикладных задач в сфере инноваций и технологического предпринимательства и расширяет фонд оценочных средств по учебным дисциплинам.

\section{Список литературы}

1. Андреева А.А. Основы рыночной экономики: прикладные задачи для студентов технических и логистических направлений подготовки : учебное пособие / А.А. Андреева, О.Ф. Быстров, Г.П. Ермошина, Д.Э. Тарасов ; под ред. Г.П. Ермошиной. - Москва : РУСАЙНС, 2021. - 136 с.

2. Быстров О.Ф. Метод БОФа в экономике и менеджменте: монография / О.Ф. Быстров. - Saarbucken: Palmarium Academic Publishing, 2013. - 96 c.

3. Тарасов Д.Э. Стратегическое управление: изменения, инновации, стартапы: монография / Д.Э. Тарасов, О.Ф. Быстров; под. Ред. Проф. О.Ф. Быстрова. - Beau Bassin: Palmarium Academic Publishing, 2020. - 105 c.

(C) А.А. Андреева, О.Ф. Быстров, 2021 